\title{
CLINICAL PREDICTION OF EARLY ONSET SEPSIS IN PRETERM NEONATES
}

10.36740/WLek202010121

\author{
Valeriy Pokhylko, Yuliia Cherniavska, Nataliia Adamchuk,Svitlana Tsvirenko, Yuliia Klimchuk \\ UKRAINIAN MEDICAL STOMATOLOGICAL ACADEMY, POLTAVA, UKRAINE
}

\begin{abstract}
The aim of the study was to analyze and identify risk factors for the development of early onset sepsis in preterm neonates and to develop a clinical prognostic model. Materials and methods: A retrospective cohort study included 152 newborns with birth weight from 1000 to $2500 \mathrm{~g}$, who were treated in the neonatal intensive care units of medical institutions in the Poltava region. Among 152 children, 121 had clinical and laboratory symptoms of infection, which were regarded as manifestations of early onset sepsis, the rest of the children $(n=31)$ had no manifestations of infection.

Results: According to the results of multiple stepwise logistic regression analysis, the predictive model has been developed. It included gestational age, visual changes of placenta, Apgar score at the 1st minute, the level of monocytes more than $6.5 \%$, the history of abortions and premature rupture of membranes. The diagnostic characteristics of the developed model had high: sensitivity $-82.2 \%$, specificity $-93.55 \%$, positive predictive value $-97.98 \%$, negative predictive value $-58 \%$.

Conclusions: The prognostic model developed by us, which showed high diagnostic characteristics, includes information on maternal risk factors, the state of the newborn immediately after birth, and biomarkers of infection (C-reactive protein and monocyte count). Therefore, we believe that when interpreting biomarkers, the decision to prescribe antibiotics should be based on the presence of maternal risk factors and clinical symptoms of infection in the prematurely born child, which may be nonspecific
\end{abstract}

KEY WORDS: premature infants, early onset neonatal sepsis, risk factors, diagnostic markers

Wiad Lek. 2020;73(10):2219-2223

\section{INTRODUCTION}

Early onset sepsis (EOS) in premature infants is the condition that has a potentially huge impact on early and long-term adverse developmental outcomes in children. Over the past decades, improvements in obstetric and neonatal services have contributed to a significant reduction in mortality, but practically did not affect the incidence of neonatal sepsis. Between 1995 and 2005 the number of cases of severe sepsis in newborns has doubled (from 4.5 to 9.7 per 1000 newborns) [1], inversely proportional to gestational age at birth and can reach $60 \%$ in the most immature infants [2]. Probably, the improvement in the survival rates of children with very low birth weight [3], as well as the presence of polymorphism of key genes that are responsible for the formation of the body's response to bacterial infection [4], led to an increase in the population of newborns susceptible to the development of intrauterine infections. Neonatal sepsis is the cause of death or severe disability in $39 \%$ of children, even with the timely initiation of antibiotic therapy [5]. In Ukraine, infections of the perinatal period, congenital pneumonia, sepsis rank III-IV in the structure of morbidity and mortality in newborns. The true frequency of this pathology among prematurely born children is unknown, since there are no clear criteria for determining the diagnosis in this cohort of children, as well as modern bacteriological methods for determining the blood culture.
To this day, the diagnosis of sepsis in premature babies remains controversial [6], since the accuracy of the key criteria for sepsis established by the Pediatric Consensus [7] has not been determined in this cohort. Symptoms and signs of sepsis in premature infants are heterogeneous, so it is difficult for a doctor to correctly and timely diagnose and assess the severity. In these cases, a conflicting decision-making dilemma arises. On the one hand, there is a desire to minimize the prescription of antibiotics, and on the other, there is strong evidence that the timely administration of antibiotics saves lives [8].

Prematurely born children represent a very heterogeneous cohort due to the peculiarities of the course of the antenatal, intrapartum periods and the period of early adaptation. Knowledge of reliable risk factors, as well as biomarkers of sepsis, can become an information basis for ensuring the decision-making process in this situation.

3370 studies were devoted to the study of biochemical criteria of sepsis, in which the diagnostic value of $178 \mathrm{sep}$ sis biomarkers was studied, but today only two are widely used - the C-reactive protein (CRP) and the procalcitonin test (PCT) [9]. However, a recent meta-analysis [10] casts doubt on the diagnostic value of these markers, and subsequent controlled studies of PCT $[11,12]$ presented conflicting results. Based on the foregoing, today it is relevant to search for EOS markers in premature babies in order to predict the development of their disease and timely prescribe antibiotic therapy. 
Table 1. Definition and ranks of prognostic variables associated with early onset sepsis in preterm infants

\begin{tabular}{|c|c|c|c|}
\hline Prognostic variables & Definition and ranks & Prognostic variables & Definition and ranks \\
\hline \multicolumn{4}{|c|}{ Somatic status of mother } \\
\hline Smoking & 0 - no, 1 - yes & Kidneys diseases & 0 - no, 1 - yes \\
\hline Mother's age & years & Diabetes mellitus & 0 - no, 1 - yes \\
\hline \multirow{2}{*}{ Cardiovascular diseases } & \multirow{2}{*}{0 - no, 1 - yes } & Thyroid gland diseases & 0 - no, 1 - yes \\
\hline & & Oncology & 0 - no, 1 - yes \\
\hline \multicolumn{4}{|c|}{ Prenatal and intrapartum factors } \\
\hline Abortions in anamnesis & 0 - no, 1 - yes & Number of labor in mother & Units. \\
\hline Miscarriages & 0 - no, 1 - yes & Duration of I period of delivery & minutes \\
\hline Stillbirths & 0 - no, 1 - yes & Duration of II period of delivery & minutes \\
\hline Hestosis & 0 - no, 1 - yes & Placenta`s detachment & 0 - no, 1 - yes \\
\hline Spontaneous abortion threat & 0 - no, 1 - yes & Cord entanglement & 0 - no, 1 - yes \\
\hline Anemia & $0-$ no, 1 - yes & Cesarian section & $0-$ no, 1 - yes \\
\hline Fetoplacental insufficiency & 0 - no, 1 - yes & Cesarian section due to hestosis & 0 - no, 1 - yes \\
\hline Polihydramnion & 0 - no, 1 - yes & Breech or foot presentation & 0 - no, 1 - yes \\
\hline Olygohydramnion & 0 - no, 1 - yes & Multiple pregnancy & 0 - no, 1 - yes \\
\hline Colpitis & 0 - no, 1 - yes & Mother's illness during childbirth & 0 - no, 1 - yes \\
\hline Premature rupture of amniotic fluid & $0-$ no, 1 - yes & \multirow{2}{*}{ Visual changes in placenta } & \multirow{2}{*}{0 - no, 1 - yes } \\
\hline The duration of the waterless gap & hours & & \\
\hline \multicolumn{4}{|c|}{ Medical, demographic and clinical factors } \\
\hline Weight & gramms & Masculine sex & 0 - no, 1 - yes \\
\hline Gestational age & weeks & $\begin{array}{c}\text { Physical development }<10 \\
\text { percentiles }\end{array}$ & 0 - no, 1 - yes \\
\hline Evaluation using Apga & scale & Primary resu & ation \\
\hline \multirow{2}{*}{ Apgar on $1^{\text {st }} \min$. } & \multirow{2}{*}{ scores } & Need in resuscitation & 0 - no, 1 - yes \\
\hline & & Oxygenotherapy & 0 - no, 1 - yes \\
\hline \multirow{2}{*}{ Apgar on $5^{\text {th }} \min$} & \multirow{2}{*}{ scores } & Trachea intubation & 0 - no, 1 - yes \\
\hline & & Artificial lung ventilation & 0 - no, 1 -yes \\
\hline \multicolumn{4}{|c|}{ Laboratory indicators } \\
\hline \multirow{2}{*}{ CRP } & \multirow{2}{*}{$\mathrm{mg} / \mathrm{l}$} & Bands & $\%$ \\
\hline & & Platelets & $10^{9} / л$ \\
\hline Blood glucose & $\mathrm{mmol} / \mathrm{l}$ & Monocytes & $\%$ \\
\hline WBC & $10^{9} / 1$ & Monocytes $>6,5 \%$ & 0 - no, 1 - yes \\
\hline Neutrophils & $10^{9} / 1$ & \multirow{2}{*}{ Urea } & \multirow{2}{*}{$\mathrm{mmol} / \mathrm{l}$} \\
\hline Immature vs mature granulocytes ratio & Units & & \\
\hline
\end{tabular}

\section{THE AIM}

To analyze and identify risk factors for the development of early-onset sepsis in preterm neonates and to develop a clinical prognostic model with high diagnostic characteristics.

\section{MATERIALS AND METHODS}

A retrospective cohort study was carried out, which included 152 newborns with birth weight from 1000 to $2500 \mathrm{~g}$, who were treated in the neonatal intensive care units (NICU) of medical institutions in the Poltava region. Of the 152 children, 121 had clinical and laboratory symptoms of infection, which were regarded as manifestations of EOS, the rest of the children $(n=31)$ had no manifestations of infection. Clinical symptoms of sepsis included the presence of tachycardia, tachypnea, desaturations, apnea, perfusion disorders, seizures, shock manifestations; laboratory signs of infection - the number of leukocytes is more than $20 \times 10^{9}$ or less than $5 \times 10^{9}$ and an increased level of $\mathrm{C}$-reactive protein. Confirmation of early onset sepsis was due to the presence of a positive blood culture, but this was not a mandatory criterion for inclusion in the main group.

We considered 52 candidate predictive variables associated with the development of EOS (Table 1). Previously identified reliable factors associated with the development of EOS, with a simple logistic regression analysis, were 
Table 2. Frequency of individual risk factors for antenatal and intrapartum periods and medical and demographic characteristics of children included in the survey

\begin{tabular}{|c|c|c|c|c|}
\hline Predictive variables & $\begin{array}{c}\text { Children with } \\
\text { EOS }\end{array}$ & $\begin{array}{c}\text { Children } \\
\text { without EOS }\end{array}$ & OR 95\% CI & $\mathbf{p}$ \\
\hline Abortion, n (\%) & $40(33,06)$ & $4(12,9)$ & $3,3(1,09-10,17)$ & 0,035 \\
\hline Duration of the II stage of labor (hours), $\mathrm{M} \pm \mathrm{m}$ & $23,9 \pm 1,39$ & $31,1 \pm 1,83$ & $0,9(0,86-0,99)$ & 0,037 \\
\hline Premature rupture of membranes, n (\%) & $73(60,33)$ & $8(25,81)$ & $4,4(1,81-10,57)$ & 0,001 \\
\hline Caesarean section due to fetal distress, $\mathrm{n}(\%)$ & $40(33,33)$ & $5(16,13)$ & $2,6(0,92-7,19)$ & 0,073 \\
\hline Mother's illness during childbirth, n (\%) & $39(32,23)$ & $5(16,13)$ & $2,47(0,88-6,92)$ & 0,085 \\
\hline Visual changes in the placenta, n (\%) & $25(20,66)$ & $1(3,23)$ & $7,8(1,01-60,10)$ & 0,013 \\
\hline Birth weight (grams), $\mathrm{M} \pm \mathrm{m}$ & $1973,9 \pm 8,36$ & $2232,2 \pm 64,2$ & $0,9(0,98-0,99)$ & 0,014 \\
\hline Gestational age, $\mathrm{M} \pm \mathrm{m}$ & $32,59 \pm 0,2$ & $35,19 \pm 0,19$ & $0,4(0,24-0,53)$ & $<0,001$ \\
\hline Apgar scale at 1 minute, $\mathrm{M} \pm \mathrm{m}$ & $6,08 \pm 0,14$ & $7,35 \pm 0,09$ & $0,1(0,05-0,31)$ & $<0,001$ \\
\hline Apgar scale at 5 minutes, $\mathrm{M} \pm \mathrm{m}$ & $6,77 \pm 0,10$ & $7,77 \pm 0,13$ & $0,3(0,16-0,49)$ & $<0,001$ \\
\hline \multicolumn{5}{|l|}{ Laboratory indicators: } \\
\hline $\mathrm{CRB}, \mathrm{M} \pm \mathrm{m}$ & $7,10 \pm 0,84$ & $4,28 \pm 1,10$ & $1,5(1,07-2,03)$ & 0,017 \\
\hline Monocytes, $\mathrm{M} \pm \mathrm{m}$ & $7,008 \pm 0,30$ & $5,32 \pm 0,57$ & $1,2(1,03-1,35)$ & 0,018 \\
\hline Monocytes> 6.5\%, n (\%) & $66(54,55)$ & $8(25,81)$ & $3,4(1,43-8,32)$ & 0,006 \\
\hline
\end{tabular}

Notes: CRP - C-reactive protein, $\mathrm{OR}$ - odds ratio, Cl - confidence interval, $\mathrm{M}$ - median, $\mathrm{m}$ - standard error.

Table 3. Distribution of variables in stepwise multiple logistic regression model

\begin{tabular}{|c|c|c|c|c|c|c|}
\hline Variables & $\boldsymbol{\beta}$ & m & OR & $95 \% \mathrm{Cl}$ & $\begin{array}{c}\text { Area under } \\
\text { ROC }\end{array}$ & $\%$ of ROC increase \\
\hline Gestational age & $-0,786$ & 0,236 & 0,455 & $0,286-0,724$ & 0,8661 & \\
\hline Premature rupture of membranes & 0,989 & 0,609 & 2,689 & $0,815-8,871$ & 0,8777 & 1,3 \\
\hline Visual changes in the placenta & 1,699 & 1,410 & 5,470 & $0,345-86,74$ & 0,8922 & 1,7 \\
\hline Monocyte count $>6.5 \%$ & 0,944 & 0,647 & 2,571 & $0,722-9,148$ & 0,9036 & 1,3 \\
\hline Apgar score for $1 \mathrm{~min}$. & $-2,076$ & 0,744 & 0,125 & $0,029-0,538$ & 0,9370 & 3,7 \\
\hline History of abortion & 1,193 & 0,865 & 3,298 & $0,604-17,99$ & 0,9377 & 0,1 \\
\hline
\end{tabular}

subsequently subjected to multiple logistic regression analysis to identify reliable risk factors and include them in the clinical prognostic model.

A 5\% significance level was used to include each variable in the model. After the final model was created, the area under the ROC (receiver operating characteristic) curve was calculated.

Constant variables are represented as mean and standard error, categorical variables as absolute numbers and percentages. Student's test was used to compare independent samples and $\chi^{2}$ test to compare proportions. All statistical analyzes were performed using the STATA v11 software package for Windows (StataCorp, Texas, USA).

\section{RESULTS}

Information from the case histories of 152 children who were included in the study was analyzed taking into account certain criteria. The average gestational age of the examined children was $33.14 \pm 2.27$ weeks, the average body weight at birth was $2026.9 \pm 509.13 \mathrm{~g}$. Among all the studied prenatal risk factors that could affect the development of EOS in children, only the presence of abortion and premature rupture of the amniotic membranes in the mother were significantly associated with development of EOS (table 2).
Among the factors of the intrapartum period, the duration of the second stage of labor, the operation of a cesarean section due to fetal distress, the mother's illness during childbirth, and visual changes in the placenta were reliable. Among the clinical and demographic factors, the weight of the child at birth, gestational age, and Apgar score at 1 and 5 minutes were significant.

As for the course of the disease, the need for the use of mechanical ventilation was in 71 (58.68\%) infants, drug support for hemodynamics - in 47 (38.84\%). Food intolerance was found in $62(51.4 \%)$ infants, episodes of arterial hypotension - in 50 (41.2\%), early jaundice - in $29(23.97 \%)$, convulsions - in $9(7.44 \%)$, oliguria - in 8 (6.6\%) and hemorrhagic syndrome - in 4 (3.31\%) children.

Of the laboratory parameters, only CRP and the level of monocytes were significantly associated with the development of EOS in premature babies. As presented in Table 2, gestational age, visual changes in the placenta, Apgar scale at 1 minute, monocyte level more than 6,5\%, history of abortion and premature rupture of membranes have the greatest influence on the development of EOS in premature infants. Therefore, these variables were included in the final predictive model chosen by stepwise multiple logistic regression analysis (Table 3 ). 


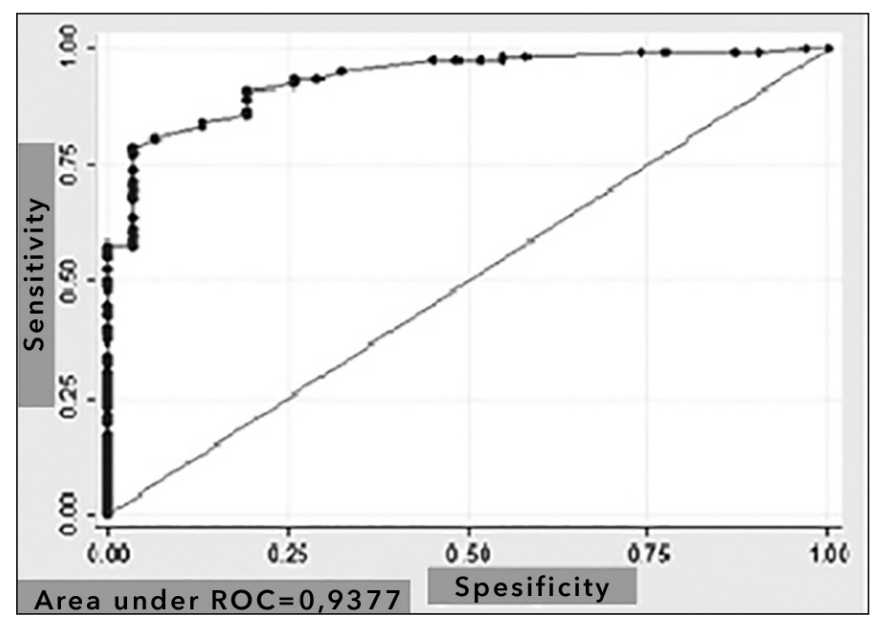

Fig. 1. ROC-curve of clinical prognostic model for the development of early onset sepsis in premature infants

The results showed that each additional week of gestational age reduces the risk of early onset sepsis $(\beta=$ -0.786), and the inclusion of this factor alone has a significant prognostic value (the area under the ROC curve is 0.8661). Subsequent incremental addition of each predictive variable increases the area under the ROC and accordingly enhances the predictive characteristics of the model. Thus, the operational characteristics of our final model, which include gestational age, maternal history of abortion, premature rupture of membranes, visual changes in the placenta, Apgar score at 1 minute, monocyte count> $6.5 \%$, were found to be quite high, namely: the sensitivity was $82.2 \%$, the specificity was $93.55 \%$, the positive predictive value was $97.98 \%$, the negative predictive value was $58 \%$, the area under the ROC curve was 0.9377 (Fig. 1).

\section{DISCUSSION}

The results of the study showed that the clinical picture of EOS is highly variable. Other authors also pay attention to nonspecific symptoms of sepsis [13-17]. Most of the symptoms related to the cardiovascular system (tachycardia / bradycardia, hypotension, poor perfusion) [18-22], the respiratory system (apnea, cyanosis, tachypnea, the need for respiratory support, and increased oxygen support) $[18,23]$, central nervous system (lethargy, hypotension and seizures), temperature changes (increase or decrease) and nutritional problems indicate the presence of difficulties in making a diagnosis $[8,18]$. A complex of antenatal (premature rupture of membranes, history of abortion), intranatal (visual changes in the placenta), clinical and demographic factors (gestational age of the child, low score on the Apgar scale) and some biomarkers are reliably associated with the data obtained on the development of early onset sepsis in prematurely born children. (level of CRP, monocytes). It should be noted that of all the biomarkers that were studied in the study, only CRP and the number of monocytes had significant value, and such well-known markers as the number of leukocytes, the proportion of immature cells, and a low number of platelets were not particularly significant. Hornik et al. [24, 25], who retrospectively studied the diagnostic value of the total number of leukocytes $\left(5,000 / \mathrm{mm}^{3}-19,000 / \mathrm{mm}^{3}\right)$, the absolute number of neutrophils $\left(\geq 1,500 / \mathrm{mm}^{3}\right)$ and the ratio of immature neutrophils to mature $(<0.2)$ in more than 200000 premature and term infants concluded that these indicators are not acceptable for identifying infants with early or late neonatal sepsis. As for the number of immature forms of leukocytes, according to the results of the study by Van der Meer et al. [23], there are wide intra- and interlaboratory variations in the interpretation of neutro phyla $(15-72 \%$, $\mathrm{SD}, 11 \%)$ and their immature forms $(4-64 \%, \mathrm{SD}, 11 \%)$. Most authors consider thrombocytopenia, hyperglycemia or hypoglycemia to be appropriate [18, 23, 8, 9, 22]. A positive culture is considered the "gold standard" for defining infection, although culture-positive clinical sepsis is rarely diagnosed in all age groups [27]. In this study, a positive blood culture was found in a minimum number of children (18.5\%). Other authors also write about similar trends. In a study by Garges it was shown that in $38 \%$ of newborns (GA less than 34 weeks) with culture-positive bacterial meningitis, the blood culture was negative [26]. It should be borne in mind that a false negative result of a blood culture may be due to a low number of bacteremia colonies in newborns or their absence in case of insufficient blood volume collected for research. Therefore, it is currently believed that if a child has negative cultures of blood or other loci, but has symptoms of suggested infection, the child should be diagnosed with clinical sepsis [27].

\section{CONCLUSIONS}

The prognostic model developed by us, which showed high diagnostic characteristics, includes information on maternal risk factors, the state of the newborn immediately after birth, and biomarkers of infection (CRP and monocyte count). Therefore, we believe that when interpreting biomarkers, the decision to prescribe antibiotics should be based on the presence of maternal risk factors and clinical symptoms of infection in the prematurely born child, which may be nonspecific.

\section{REFERENCES}

1. Hartman M.E., Linde-ZwirbleW.T., Angus D.C. Trends in the epidemiology of pediatric severe sepsis. Pediatr Crit Care Med. 2013; 14:686-93.

2. Stoll B.J., Hansen N.I., Bell E.F. Eunice Kennedy Shriver National Institute of Child Health and Human Development Neonatal Research Network: Neonatal outcomes of extremely preterm infants from the NICHD Neonatal Research Network. Pediatrics. 2010; 126:443-56.

3. Klinger G., Levy l., Sirota L. Epidemiology and risk factors for early onset sepsis among very-low- birthweight infants. Am J Obstet Gynecol. 2009; 201(1):38.e1-6.2.

4. Znamienskaia T.K., Kovaliova 0.M., Pokhylko V.I. et al. Asiciacia mizh polimorfizmom GSTT1, GSTM1, GSTP1 geniv u indyviduumiv ta skhylnistiu ikh do okremykh zakhvoriuvan. Perynatologia ta pediatria. 2012; 3:51.

5. Brocklehurst P., Farrell B., King A. Treatment of neonatal sepsis with intravenous immune globulin. N Engl J Me D. 2011; 365:1201-11. 
6. Wynn J.L., Wong H.R., Shanley T.P.Time for a Neonatal-Specific Consensus Definition for Sepsis. Pediatr Crit Care Med. 2014; 15(6):523-8.

7. Dellinger R.P., Levy M.M, Carlet J.M. Surviving Sepsis Campaign: International guidelines for management of severe sepsis and septic shock. Intensive Care Med. 2008; 34:17-60.

8. Kumar A., Roberts D., Wood K.E. Duration Of hypotension Before Initiation OfEffective Antimicrobial Therapy IS The Critical Determinant Of Survival In Human Septic Shock. Crit Care Med. 2006; 34:1589-96.

9. Pierrakos C., Vincent J.L. Sepsis biomarkers: a review. Crit Care. 2010; $14: 15$.

10. Tang B.M., Eslick G.D., Craig J.C. Accuracy of procalcitonin for sepsis diagnosis in critically ill patients: systematic review and meta-analysis. Lancet Infect Dis. 2007; 7:210-7.

11. Bouadma L., Luyt C.E. Use of procalcitonin to reduce patients'exposure to antibiotics in intensive care units (PRORATA trial): a multicentre randomised controlled trial / PRORATA trial group. Lancet. 2010; 375:463-74.

12. Horan T.C., Andrus M., Dudeck M.A. CDC / NHSN surveillance definition of health care-associated infection and criteria for specific types of infections in the acute care setting. Am J Infect Control. 2008; 36:309-32.

13. Been J.V., Rours I.G., Kornelisse R.F. Histologic chorioamnionitis, fetal involvement, and antenatal steroids: Effects on neonatal outcome in preterm infants. 2009; 201:587.

14. Wynn J.L., Wong H.R., Shanley T.P.Time for a Neonatal-Specific Consensus Definition for Sepsis. Pediatr Crit Care Med. 2014; 15(6):523-8.

15. Dutta S., Levy M.M, Carlet J.M. Intrapartum antibiotics and risk factors for early onset sepsis. Arch Dis Child Fetal Neonatal Ed. 2010; 95:99-103.

16. Kuhn P.A., Messer J., Paupe A. Multicenter, randomized, placebocontrolled trial of prophylactic recombinant granulocyte-colony stimulating factor in preterm neonates with neutropenia. J Pediatr. 2009; 155:324-30.

17. Manzoni P., Rinaldi M., Cattani S. Italian Task Force for the Study and Prevention of Neonatal Fungal Infections, Italian Society of Neonatology: Bovine lactoferrin supplementation for prevention of late-onset sepsis in very low-birth-weight neonates: A randomized trial. JAMA. 2009; 302: 1421-28.

18. Auriti C., Fiscarelli E., Ronchetti M.P. Procalcitonin in detecting neonatal nosocomial sepsis. Arch Dis Child Fetal. Neonatal Ed. 2012; 97:368-70.

19. Horan T.C., Andrus M., Dudeck M.A. CDC / NHSN surveillance definition of health care-associated infection and criteria for specific types of infections in the acute care setting. Am J Infect Control. 2008; 36:309-32.

20. Mercer B.M., Crouse D.T., Goldenberg R.L. Eunice Kennedy Shriver National Institute of Child Health and Human Development MaternalFetal Medicine Units Network: The antibiotic treatment of PPROM study: Systemic maternal and fetal markers and perinatal outcomes. Am J Obstet Gynecol . 2012; 206: 145.e1-9.
21. Tita A.T., Landon M.B., Spong C.Y. Eunice Kennedy Shriver NICHD MaternalFetal Medicine Units Network: Timing of elective repeat cesarean delivery at term and neonatal outcomes. N Engl J Med. 2009; 360:111-20.

22. Mitha A., Foix-L'Hélias L., Arnaud C. EPIPAGE Study Group: Neonatal infection and 5-year neurodevelopmental outcome of very preterm infants. Pediatrics. 2013; 132:372-80.

23. Goldstein B., Giroir B., Randolph A. Consensus Conference on Pediatric Sepsis: International pediatricsepsis consensus conference:Definitions for sepsis and organ dysfunction in pediatrics. Pediatr Crit Care Med. 2005; 6:2-8.

24. Hornik C.P., Benjamin D.K., Becker K.C. Use of the complete blood cell count in early-onset neonatal sepsis. Pediatr Infect Dis J. 2012; 31:799-802.

25. Hornik C.P., Benjamin D.K., Becker K.C. Use of the complete blood cell count in early-onset neonatal sepsis. Pediatr Infect Dis J. 2012;31:803-7.

26. Garges H.P., Moody M.A., Cotten C.M. Neonatal meningitis: What is the correlation among cerebrospinal fluid cultures, blood cultures, and cerebrospinal fluid parameters? Pediatrics. 2006; 117:1094-100.

27. Wynn J.L., Wong H.R., Shanley T.P.Time for a Neonatal-Specific Consensus Definition for Sepsis. Pediatr Crit Care Med. 2014; 15(6):523-8.

This article was written in the frames of Scientific research works: "To develop and to implement a system of medical and psychological support for newborns at risk of chronic morbidity, disability and developmental delay”, N0117U004538 and "To develop the clinical and laboratory criteria, methods for predicting and preventing metabolic disorders in children of early age”, N $0120 U 102856$.

\section{ORCID and contributionship:}

Valeriy Pokhylko: 0000-0002-1848-0490 ${ }^{A, F}$

Yuliia Cherniavska: 0000-0002-4522-7538 ${ }^{B, D}$

Nataliia Adamchuk: 0000-0001-5868-6031 ${ }^{A, E}$

Svitlana Tsvirenko: 0000-0002-2304-9136

Yuliia Klimchuk: ${ }^{C, D}$

\section{Conflict of interest:}

The Authors declare no conflict of interest

\section{CORRESPONDING AUTHOR Yuliia Cherniavska}

Ukrainian Medical Stomatological Academy,

Department of Pediatrics №1 with Propedeutics and Neonatology

23, Schevtchenka str, Poltava, Ukraine, 36000

tel: +380661186555

e-mail:ycherniavska32@gmail.com

Received: 04.06.2020

Accepted: 31.08 .2020

A - Work concept and design, B - Data collection and analysis, C - Responsibility for statistical analysis, D - Writing the article, $\mathbf{E}$ - Critical review, $\mathbf{F}$ - Final approval of the article 